\title{
Advancing Rights-Based Family Planning from 2020 to 2030
}

\author{
Karen Hardee (D) ${ }^{1}$ \\ Sandra Jordan ${ }^{2}$
}

'Executive Office, What Works Association, Arlington, VA, USA; ${ }^{2}$ Public Health Consulting, Bethesda, MD, USA
Correspondence: Karen Hardee; Sandra Jordan

Email KHardee@hardeeassociates.com; sandrajordan4@gmail.com
Introduction: An assessment in 2019 by Family Planning 2020 of progress on rights-based family planning since 2012 highlighted the development of tools and guidelines that identify and explain rights in relation to family planning, promotion of rights-based approaches to programing, strengthened accountability, and measurement of rights-focused outcomes. The assessment was also forward-looking, asking what aspects of rights-based family planning still need attention moving from 2020 to 2030 .

Methods: This paper draws on interviews with 23 key informants from governments, civil society, and youth focused organizations, implementing partners, and bi-lateral and multilateral organizations from Africa, Asia and the Pacific, Europe and North America, all working on family planning and engaged in various roles with the FP2020 partnership at global and national levels, along with documentation of FP2030 partnership plans. The interviews were conducted as part of the assessment and included questions to respondents for their recommendations on rights-based family planning moving towards 2030.

Results: Respondents agreed that rights should be at the center of the vision for family planning, with attention to rights literacy, accountability and equity, including adolescent and youth leadership. They noted the need for consistent political and financial support, and incorporating rights into result-based financing programming. While respondents noted the need for development and dissemination of practical tools and training materials, along with rights metrics and implementation research, they stressed the importance of focusing work on rights at the country level. Respondents also acknowledged that institutionalizing rightsbased family planning will require enhanced commitment and funding from both donors and countries to ensure programming - and success - over the long term. Amplifying civil society and particularly adolescent and youth voices will be key to engaging governments to support both rights-based programming and provide funding. Review of initial planning under FP2030 related to each of the recommendations suggests that the new partnership is seeking to addressing each of them.

Discussion: As the family planning field looks beyond 2020 to 2030, this paper provides a roadmap for building on the gains made over the past decade to effectively tackle the challenges remaining to ensure that programming to achieve the vision of the FP2030 Partnership is rights-based.

Keywords: human rights, family planning, contraception, accountability, FP2030

\section{Plain Language Summary}

The numeric goal announced at the 2012 London Summit on Family Planning (FP) sparked work to ensure that achieving the goal was undertaken through programming that respects, protects and fulfills human rights enshrined in human rights conventions and in the 1994 International Conference on Population and Development. This paper draws on 23 interviews 
in 2019 with key informants working on FP and engaged with the FP2020 partnership, along with documentation of FP2020 and the FP2030 partnership.

Respondents noted progress, particularly tools and guidelines identifying and explaining rights in relation to $\mathrm{FP}$, promotion of rights-based approaches to programing, strengthened accountability, and measurement of rights-focused outcomes. Moving forward, they recommended: Focusing on country-level rights literacy and implementation, with accountability and continued work on metrics and evidence generation and dissemination. Institutionalizing rights-based FP will require enhanced commitment and funding over the long term.

Review of initial planning under FP2030 related to each of the recommendations suggests that the new partnership is seeking to addressing each of them. This paper helps provide a roadmap for not only building on the gains made over the past decade and to effectively tackle the challenges remaining to ensure rights-based programming to achieve the vision of FP2030.

\section{Background}

A press release from the 2012 London Summit on Family Planning, organized by the Bill \& Melinda Gates Foundation and the UK Department for International Development, pronounced that the summit

Will mobilize commitments to support the rights of an additional 120 million women and girls in the world's poorest countries to use contraceptive information, services and supplies, without coercion or discrimination, by 2020 (https://www.familyplanning2020.org/sites/ default/files/About the London_Summit_on_FP_Summary_Document.pdf)

The emphasis on rights responded to concerns by civil society that having a numeric goal for the initiative represented a retreat from the human rights-centered approach that emerged from the 1994 International Conference on Population and Development (ICPD) framework for sexual and reproductive health. ${ }^{1-4}$

The Family Planning 2020 (FP2020) Partnership constituted to achieve the goal of the 2012 London Summit, composed of governments, civil society, multilateral organizations, donors, the private sector, and nongovernmental organizations (NGOs), with support from a secretariat, was challenged to ensure that human rights grounded in the ICPD framework were at the center of programming. A 2019 assessment of the measures FP2020 and partners took to ensure the rights of women and girls to contraception after 2012 highlighted, among other actions, efforts undertaken to develop tools and guidelines that identify and explain rights in relation to family planning, to promote programming implemented through rights-based approaches, to strengthen accountability, and to measure outcomes from a rights lens. ${ }^{5}$

At the close of 2020, the vision for moving family planning forward to 2030 was announced as the new iteration of the initiative was launched. FP2030's vision is not numeric; instead envisions

A future where women and girls everywhere have the freedom and ability to lead healthy lives, make their own informed decisions about using contraception and having children, and participate as equals in society and its development. (http://www.familyplanning2020.org/ $\underline{\text { Building2030) }}$

FP2030's vision is underpinned by principles of voluntarism, rights, equity, and accountability. Building on the momentum on rights-based family planning over the past decade, what is needed to ensure rights under moving to 2030 ?

The 2019 assessment of progress on rights-based family planning was also forward-looking, with recommendations on strengthening rights-based family planning offered by respondents from the family planning community. This paper focuses on key recommendations and how they can guide programming over the next decade. The paper also reviews initial planning under FP2030 related to each of the recommendations to assess if and how the new partnership is seeking to address them.

\section{Methods}

This paper draws on interviews with 23 key informants working on family planning and engaged in various roles with the FP2020 partnership at global and national levels, along with documentation of FP2030 partnership plans. The interviews were conducted as part of an assessment of contributions made by FP2020 in advancing rightsbased family planning, conducted in 2019 rather than under a research protocol. ${ }^{5}$ The assessment did not go through ethics review, although the authors asked respondents to provide written informed consent to participate in the key informant interviews and for their quotes to be used. All participants agreed. The key informants represented governments (2), civil society and youth focused organizations (9), implementing partners (4), and bi-lateral /multilateral organizations and foundations (8). Key informants were based in Africa, Asia and the Pacific, Europe, 
and the United States. The key informants were selected purposively both to provide geographic perspective and to include stakeholders who were involved in service provision, oversight or development of family planning programs, in their country and/or organization, and who had familiarity with FP2020. Time and resource considerations associated with the overall assessment in which the interviews were conducted determined the sample size. The authors developed an interview guide, including two forward-looking questions that are the focus of this paper: 1) what more needs to be done, in your opinion, to promote right-based FP? (Prompt: Think of the global, country and community levels); and 2) If you could give advice to those developing the vision for FP at 2030 related to rights-based family planning, what advice would that be?

The key informants, most interviewed by the authors but with some responding electronically. The interviews lasted between 30 minutes to one hour. The authors reviewed the written responses to the questions, from which emergent themes formed the recommendations. For purposes of reflecting comments from respondents in this paper, they are designated in three groups: Nongovernmental organization (NGO), development partner, and national government. Quotes from respondents are italicized.

To identify what steps FP2030 is taking related to each of the recommendations, the authors reviewed the FP2030 website, along with other literature on components of rights-based family planning. The relevant literature was identified as part of the 2019 assessment to identify progress since 2012, through the authors' knowledge of rights-based family planning activities and studies, and through Google searches.

\section{Results}

This section begins with a description of the advances made through 2020 to promote rights, followed by key recommendations from respondents to accelerate the momentum towards embedding rights in family planning programming.

\section{Achievement in Rights-Based Family Planning Since 2012 Articulating Human Rights for Family Planning} Although family planning had been proclaimed a human right at the 1968 International Human Rights Conference, ${ }^{6}$ in 2012 there was not a common language or understanding of rights concepts related to family planning explicitly (rather than implicitly) included under the umbrella of sexual reproductive health and rights SRHR), or about how to translate rhetoric about rights at high levels into concrete, actionable steps required at different levels in the health system. There was a clear need at the time to bridge the

Chasm between theory and practice ... in translating human rights norms into concrete programming guidance applicable in diverse policy contexts and national circumstances. $^{7}$

In 2011, the United Nations Population Fund (UNFPA) and the Center for Reproductive Rights (CRR) produced a briefing paper that highlighted human rights related to contraception $^{8}$ and UNFPA published its 2012-2020 family planning strategy that was underpinned by human rights. ${ }^{9}$ On the eve of the London Summit in 2012, Cottingham et al published an article with examples of how family planning programming could be strengthened by infusing human rights values and concepts into all aspects of programming. ${ }^{10}$ This was followed in 2013 by publication of a conceptual framework providing a vision for what a voluntary, rights-based family planning program entails at the policy, service delivery, community, and individual levels. ${ }^{11}$ The framework illustrated a holistic family planning program that respects, protects, and fulfills human rights - expressed in programmatic terms and couched in family planning programming literature and experience.

The framework drew on human rights work by Erdman and Cook, ${ }^{12}$ who identified three broad categories of reproductive rights among the composite of human rights that are

Guaranteed in national laws, constitutions, and regional and international treaties that can be applied to protect against the causes of ill health and promote sexual and reproductive well-being.

These categories, which clearly relate to family planning, include:

1. Rights to reproductive self-determination (the rights of couples and individuals to decide freely and responsibly the number and spacing of their children)

2. Rights to sexual and reproductive health services, information, and education (including contraception) 
3. Rights to equality and nondiscrimination (right to make decisions concerning reproduction, including family planning, free of discrimination, coercion, and violence)

Noting its mandate to help member states achieve the goal of the highest attainable standard of health for all, including sexual and reproductive health, and that respecting, protecting, and fulfilling human rights is critical for family planning services, WHO produced guidance on ensuring human rights in contraceptive information and services. ${ }^{13}$ In 2015, FP2020 also published Rights and Empowerment Principles that reinforced its commitment to rights. ${ }^{14}$ Box 1 lists the rights highlighted by WHO.

UNFPA and WHO further linked the rights principles and standards from WHO to eight categories of action that can be taken at different levels of the health system to fulfill human rights in family planning programming, including, for example, advancing the human rights standard of availability through strengthening contraceptive commodities, logistics, and procurement; and promoting non-discrimination by ensuring access to contraceptive information and services for all. ${ }^{15}$ To further augment its 2014 guidance, WHO published a checklist for health care providers working at the primary health care level who provide contraceptive information and services. ${ }^{16}$ The checklist is intended to be used to identify quality of care issues and link them with human rights standards, with suggestions for improvements. FP2020 produced an accompanying accountability tool for civil society to

To evaluate local and national contraceptive programs and empower activists to begin or continue advocating with their governments for rights-based contraceptive information and services. ${ }^{17}$

Box I WHO's Ensuring Human Rights in the Provision of Contraceptive Information and Services

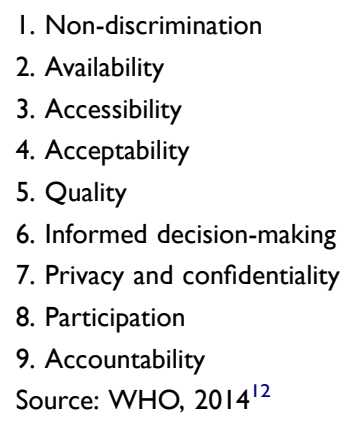

Kumar et al explained that "applying a rights lens reframes the way we typically think about programs, including how we define goals, what we value, and what we measure" and ideally should include incorporating rights principles and standards in all phases of programming - from assessment and design, to implementation, and to monitoring and evaluation. ${ }^{18}$

\section{Convening Stakeholders to Share Experiences with Rights-Based Family Planning}

FP2020 served as a conduit for socializing rights-based family planning, including through webinars, a dedicated page on its website, and co-hosting a series of meetings, including the latest at the 2018 International Conference on Family Planning focused on rights in practice. ${ }^{19-21}$ Hailing from 10 countries, participants included human rights lawyers, clinic directors and practitioners, advocates, youth representatives, country development partners and foundations, researchers, midwives, and activists. Presentations highlighted successes at the legal and policy level, reaching marginalized groups, and expanding access to services and identified continuing challenges, including the need to bring rights discourse out of the realm of treaties and conventions to speak to people's lived experience and to strengthen rights literacy among both duty bearers (governments) and rights holders (individuals).

\section{Implementing Programming}

Work to implement rights-based programming was undertaken at the country level, although documentation of this programming is scant. Two program interventions, one in Nigeria and one in Uganda, attempted to incorporate all rights principles and standards related to family planning identified by $\mathrm{WHO}^{13}$ and FP2020 ${ }^{14}$ and to incorporate them at the service delivery level as identified in the Voluntary, Human Rights-based Conceptual Framework. ${ }^{11}$ Similar and/or adapted tools and approaches were used during the implementation and results measurement at the service delivery level in both countries' programs. The programs, implemented between 2016 and 2017, shared some common components, including building provider capacity, implementing facility level action plans, increasing clients' knowledge of their rights, and strengthening health committee structures to support voluntary rights-basedfamily planning. The interventions in both countries, which built on existing programs, resulted in beneficial outcomes, including improved quality of care, reduced provider bias, and greater awareness among providers and clients about 
what constitutes rights vulnerabilities and abuses and willingness to report rights issues. Other common lessons that emerged included the continued importance of promoting rights literacy among all stakeholders; the need to strengthen health systems; the importance of strong and supportive supervision to reinforce provider provision of rights-based information and services; and the need to work on rights at multiple levels, including policy, community, and individual levels to reinforce interventions at the service level. ${ }^{22}$

Measurement. There have been advances over the past decade in monitoring and evaluating family planning programming from a human rights perspective to address the challenge that

While many agencies and organizations work to integrate human rights into public health policies and programs .... they often struggle to monitor and evaluate how well human rights are actually being addressed or fulfilled in these efforts. ${ }^{23}$

FP2020 included indicators to measure rights and empowerment in its core indicators and its quest to expand measurement of rights-based family planning (http://www. familyplanning2020.org/data-hub). Among their 18 core indicators, FP2020 monitored several indicators related to ensuring that women and girls have the ability to make a full, free, voluntary, and informed choice in selecting the method that will best meet their needs. Acknowledging early on that available indicators did not do justice to measuring rights-based family planning, questions related to aspects of rights, namely quality, equity, and accountability were added to the National Composite Index on Family Planning (NCIFP), which was fielded in 2014 and $2017 .^{24,25}$ Through 22 questions across the three components of quality, equity, and accountability, the NCIFP was able to go in depth into these important aspects of rightsbased family planning. For example, for equity respondents are asked the extent to which policies are in place to prevent discrimination towards special sub-groups such as youth, the poor, people living with HIV, or those seeking post abortion care, and the extent to which providers discriminate against these groups. The accountability questions ask, as one example, about mechanisms in place to monitor rights violations and if such violations are reviewed on a regular basis. The 22 questions related to quality, equity, and accountability are available at (http://www.track20.org/ pages/data_analysis/policy/NCIFP.php). Comparison of scores from 2014 and 2017 showed that scores for quality, equity, and accountability all rose. ${ }^{25}$
As part of its work to identify and explain the human rights principles and standards associated with contraceptive information and services, WHO has published related indicators. ${ }^{13,26}$ To identify the indicators, Gruskin et $\mathrm{al}^{23}$ developed a methodology to assess indicators for their human rights sensitivity - along with their public health validity. From this analysis, WHO prioritized 20 indicators (with an additional 21 rights indicators listed in an annex) related to ensuring access for all; commodities, logistics and procurement; organization of health-care facilities, outreach and integration; quality of care; comprehensive sexuality education; participation by potential and actual users of services; and accountability to those using services. ${ }^{26}$

Since 2012, a number of studies have or are being conducted to advance understanding of right-based family planning and outcomes associated with it. Two implementation studies using a similar data collection package sought to address all of the rights principles and standards (listed in Box 1) at the service delivery level in Nigeria and Uganda. ${ }^{22,27}$ Other studies have addressed aspects of rightsbased family planning, including a study on contraceptive autonomy that yielded a measure that incorporates a rights perspective by defining contraceptive autonomy; ${ }^{28}$ quality, rights-based counseling, ${ }^{29,30}$ providing full, free and informed choice $;{ }^{31-33}$ measuring quality of care $;{ }^{34-36}$ reproductive empowerment, ${ }^{37,38}$ and reproductive coercion. ${ }^{39}$ Evidence is also emerging from studies on social accountability. $^{40-43}$ The Performance Monitoring and Accountability (PMA) Project, formerly PMA2020, includes measures of access, equity, quality, and choice in their surveys (https://www.pmadata.org).

\section{Reflections of Respondents About Achievements from 2012-2019}

Respondents agreed that FP2020 had provided a strong platform for promoting rights-based family planning, including through "translation of the human rights conventions into practical tools and guidance for implementation" (NGO respondent), through elevating the discourse on rights-based family planning, and through serving as a "resource center for materials on rights-based family planning and for coordinating partners" (development partner respondent). One NGO respondent cautioned that we should not malign programming before 2012 as though none of it was rights-based, but they reflected that "the platform has provided an opportunity to interrogate it and 
to raise its visibility. The Summit gave the issue lift and added resources."

Respondents noted that the emphasis on rights after 2012 has helped the field articulate how taking a human rights-based approach goes beyond attention to quality of care. NGO respondents explained that said "Before the London Summit, there was more of a QOC perspective to programming," "Quality of care was the comfort zone for the family planning field," and

Introduction of the rights framework, and particularly 'AAAQ' [availability, accessibility, acceptability, and quality], caused a mind shift, helping us move beyond just a focus on quality.

Indeed, the focus on quality of care in family planning started in the 1980s and gained momentum in 1990s and 2000 s as a way to offer more client-centered care after ICPD. ${ }^{44-48}$ Quality of care is still a critical part of human rights-based family planning, ${ }^{49-}$ with the landmark quality of care framework first published in 1990 updated in the context of human rights. ${ }^{50}$ An NGO respondent summed up FP2020's contribution by saying that "While ICPD formed the foundation of rights, FP2020 has moved rightsbased family planning forward." Another NGO respondent agreed, saying "Rights-based family planning was there, but it was embedded in SRHR. The "how" of rights-based planning had not been articulated."

\section{Recommendations Moving Forward to 2030 with Rights-Based Family Planning}

Box 2 shows seven key recommendations from respondents. Each of these recommendations is discussed below,

Box 2 Key Recommendations on Rights-Based Family Planning Moving to 2030

- Keep rights at the center of the vision for family planning, promote rights literacy, and be flexible with language

- Focus at the country level

- Promote political and financial support for rights-based family planning at the global and country levels and incorporate rights into results-based financing programming

- Pay more attention to accountability

- Focus on equity and highlight adolescent and youth leadership

- Support development and dissemination of practical tools and training materials

- Continue working on rights metrics and studies and disseminate results along with steps FP2030 is taking to address the recommendations.

Keep Rights at the Center of the Vision for Family Planning, Promote Rights Literacy, and Be Flexible with Language

Respondents were clear that rights should be at the center of family planning moving to 2030. One development partner respondent echoed all respondents' certainty that rights, with a focus on women's autonomy, must be at the core of family planning:

Rights must remain front and center. We also have to remind people that family planning is not just a matter of getting products out there, essential and complex as that is. It's also about the clinic setting and how people are treated in the clinic ... It's about the policies, laws, and social norms that uphold rights, that give women the access, the quality of care, the respect, the ability to make informed decisions.

A first step is the need to increase rights literacy among all stakeholders, from policymakers down to communities and clients, in addition to program implementers and donors. An implementing partner respondent reflected that "there is so much more to do to ensure citizens' rights; demanding rights; educating people that they have rights." Respondents noted that it is not reasonable to expect providers to adhere to rights if they do not know what clients' rights are. An NGO respondent added that services need to keep pace with rights literacy and increasing demand within communities, saying,

It is one thing to give information about rights-based family planning and all of the available commodities/ method mix, but it is a totally different thing to go to the health facilities to access the same commodities and they are not in supply. The supply chain should match up with the demand generation/creation.

Another NGO respondent noted the need to link supply and demand strategies and to link rights to family planning and SRH to other rights, such as economic and social rights, noting that "Demand = agency in many areas of life - not just family planning or even SRH." Another development partner respondent agreed that the focus on rights in relation to services is too narrow a view of rights, which is "more about power than programs .... the focus should be on autonomy, agency, participation, and voice." 
Some respondents cautioned about being flexible about rights language and to focus on language that is context-appropriate. One NGO respondent explained that "some countries don't want to talk about rights" while another NGO respondent noted the challenge that "the concept of 'rights' may not get political will." Another challenge could include the level of understanding about rights among different partners. While rights language is common among civil society in talking with some governments and donors, it may prove more productive to talk about the components of rights, such as voluntarism, access, quality, or equity. Promoting rights literacy will be further achieved through flexibility in use of rights language. One NGO respondent explained that when talking with the government in their country,

Rather than talking about rights, they stressed voluntarism for family planning to ensure that there was no pressure put on clients and they used the cafeteria approach to promote contraceptive choice, including natural methods.

This combination of direct and indirect reference to rights is evident throughout the FP2030 partnership. An articulation of the FP2030 vision as a results statement that is measurable includes more dimensions of rights, again without mentioning the term rights:

The change we wish in the world is "Voluntary modern contraceptive use by everyone who wants it, achieved through individuals' informed choice and agency, responsive, and sustainable systems providing a range of contraceptives, and a supportive policy environment.]'. (https:// familyplanning2020.org/Building2030)

One of four principles underpinning FP2030 mentions rights directly:

Voluntary, person-centered, rights-based approaches, with equity at the core: ....Every decision, action, and investment made by the partnership will reflect this belief - that each person has the same right to quality family planning, regardless of their geography, socioeconomic status, gender, or culture.

On its commitments page, FP2030 "invites governments to make rights-based family planning commitments to support the partnership's vision" and further asks "that all commitment makers include rights-based approaches and accountability mechanisms or agreements" (https://commit ments.fp2030.org/). The commitments page includes information on anchoring country commitments in rights-based approaches. The page includes a framework to show countries and implementers what a Comprehensive Human Rights-based Voluntary Family Planning Program would look like, building on work since 2012 to identify rights principles and standards related to family planning and operationalizing rights-based family planning at all levels, including policy, service delivery, community, and individual. ${ }^{51}$ ]

\section{Focus at the Country Level}

Respondents stressed that considerable conceptual work and development of guidance and tools on rights-based family planning has taken place since 2012 and that work moving forward should continue to focus on country implementation of rights-based programming, with careful consideration of country context. A development partner respondent said that the global discussion needs to permeate down to countries, noting "I've heard some countries say that if they provide the right family planning services, they are providing rights-based FP - so what's the problem?"

Recommendations included further socializing rights from the national to local level being cognizant of turnover and the need for continued discussion about rights, taking a systems approach to implementing rights-based family planning, and making rights a norm through investing in advocacy. An NGO partner respondent noted advocacy is needed "because rights won't be fully integrated until [they are] in the public health system." A development partner respondent explained the need to "cascade it down to countries, understanding cultural contexts and using data to interrogate issues and identify enablers and segment the market for equity." Another development partner added, "it would be good to do an audit or mapping of rights-based family planning in FP2020 countries and then support the countries to address issues." An NGO respondent noted that "there are structural barriers specific to countries that need to be addressed as rights barriers."

In addition to countries making commitments to rights-based family planning through FP2030, they can also ensure that rights are enshrined in policies and strategies and are embedded in costed implementation plans CIPs) that serve as a multi-year actionable roadmap designed to help governments achieve their family planning goals. As of mid-2019, more than 40 CIPs had been developed, largely focused at the national level. Eight countries had completed their first-round CIPs and developed second round CIPs (https://www.familyplan 
ning2020.org/countries). The CIPs developed from 2012 to 2013 show few mentions of rights. However, those created in 2014 and later showed increased attention to rights, although the plans contained little detail about how they would be operationalized in family planning programs. CIPs developed since 2016 tend to include more detailed language on human rights. For example, Kenya's 2017-2020 CIP notes that rights-based programming

Aim[s] to fulfill the rights of all individuals to choose whether, when, and how many children to have to act on those choices through high quality SRH services and information and education; and to access those services free from discrimination, coercion, and violence. ${ }^{52}$

This is significant advance from Kenya's first CIP (20122016) which made no mention of rights.

As another example, Mali's first CIP (2014-2018) mentioned rights in relation to the country's 2002 Reproductive health Law No. 02-044 that recognized women's rights to reproductive health and family planning. The CIP noted that more than 10 years after its promulgation the law exists but is insufficiently implemented. ${ }^{53}$ The CIP sought to strengthen stakeholders' understanding of the rights of women, and specifically included providers, noting their need for training that incorporates rights. Mali's second CIP (2019-2023) also mentions the $2002 \mathrm{RH}$ law but includes more detail about rights-based family program planning. ${ }^{54}$ Mali's CIP references incorporates components of FP2020's Rightsizing Family Planning toolkit that was developed in 2018 whatever to help guide programs. ${ }^{55}$ The vision of Mali's second CIP is that the family planning needs of women, young people, vulnerable groups, and couples would be met by 2023 through commodities and services that respect human rights through programing that is accountable to beneficiaries. Activities in Mali's second CIP related to rights include attention to ensuring availability of contraceptives, training of staff, and supervision, among other initiatives.

Respondents noted that NGOs have been more flexible in incorporating rights into their programming. One youth NGO respondent explained:

Being a youth-led advocacy organization on family planning, rights-based family planning has been at the core of our programming as we stand for access to not only accurate, comprehensive information but also access to services with a wide range of methods/commodities to select/choose from. In our programs and activities, we always put the client first, we don't discriminate, or segregate, and information is taken as a right of everyone including adolescents.

A different NGO respondent reported they adjusted their programming to more clearly put clients at the center to meet their rights, while another said their organization used the Voluntary Rights-based Family Planning Conceptual Framework ${ }^{11}$ to develop a road map for their programs and to conduct a rights audit of their work. Another NGO respondent noted that they talked about rights related to family planning in their country before 2012, but this was reinforced because of FP2020, which "provided a constancy of the application of the rights approach .... including in the focus on young people."

Promote Political and Financial Support for Rights-Based Family Planning at the Global and Country Levels

Cognizant of how much the political landscape changed between 2012 and 2019 when they were interviewed, both development partner and NGO respondents noted that work on rights-based family planning received varied support through the FP2020 timeframe. They also observed that donors have not been consistent in funding rights-based initiatives, noting that rights were viewed by some at the global and national levels as an expensive add-on. A development partner respondent noted that attention to and funding for rights-based family planning has been "too little, uncoordinated, and confusing to follow." Additionally promising programming was losing funding given shifting political sands and changing donor priorities. Respondents stressed that "continued advocacy for political and financial support for rightsbased family planning at the global and national country levels will be important" (development partner respondent). An NGO respondent added, "We need to mobilize the community to invest in advocacy because rights won't be fully integrated until [they are] in the public health system." Another development partner respondent noted that "if donors demand that rights-based family planning is a requirement for funding, it will become the norm."

Some respondents said that budgets for family planning do not currently reflect rights as a priority. An NGO respondent focused on country level concerns, asking,

How do we embed the rights into the program so that when countries stand up and begin paying for FP, they 
embrace rights and AAAQ [availability, accessibility, acceptability, and quality] as their own?

An NGO respondent described the need for

Shifting attention away from just budgeting for commodities, to budgeting for things that will improve rights. For example, how can we incentivize rights-based approaches, such as providers reaching out to youth?

Other respondents underscored the need for civil society organizations (CSO) to be more fluent with budget advocacy work, to strengthen their effectiveness in advocating for reproductive health budgets.

Some respondents encouraged coordinating resultsbased financing and rights-based family planning. One development partner respondent said,

We have an urgent need for guidance on how to ensure rights in results-based financing/performance-based financing work. How do we measure progress, outcome, and impact through the eyes of clients - women and girls? What do we do to avoid perverse incentives?

This includes perverse incentives created, even if inadvertently, by programs that push certain methods of contraception. Declining to use contraception should also be a choice. Another development partner explained that rights means

Choice, control for and by the individual to use - or not use - family planning. If someone decides not to use family planning, it should be on the basis of having information about FP on which to decide - not due to ignorance. That a user can stop or switch methods with no pressure.

The need to ensure that family planning programs funded through Performance Based Financing (PBF) mechanisms are underpinned with rights-based approaches has also been highlighted by advocates, program implementers, donors, and researchers. Promoting voluntary rightsbased family planning is crucial to ensure that family planning clients are not pressured to use services by providers expected to meet targets set by PBF programming. ${ }^{56-58}$

Eichler et $\mathrm{al}^{59}$ provided guidance on ensuring adherence to rights in $\mathrm{PBF}$, noting that:

Strategic purchasing should reflect rights-based principles of voluntarism, informed choice, quality, and accountability. In many cases, these rights-based principles are specified in policy statements and not well translated into the operational documents that govern the details of strategic purchasing.

Similarly, the push to expand access to family planning within Universal Health Coverage (UHC) is underpinned by human rights. ${ }^{60,61}$

\section{Pay More Attention to Accountability}

A number of respondents said that more work is needed to promote accountability, including policy and budget accountability, ${ }^{62,63}$ and social accountability, for citizens and communities as rights-holders to hold duty-bearers, including officials and providers, to account. Several respondents underscored the need for accountability, but each pointed to the responsibilities of others, showing that a more holistic and comprehensive approach is needed. For example, one development partner respondent described social accountability as "rights realization on the front lines." Yet, an implementing partner described work on social accountability as "just scratching the surface. Donors aren't giving enough attention to or providing funding for social accountability work related to family planning." A development partner respondent added,

We haven't engaged enough with civil society at the country level. If we leave it to clinical and program staff, it might not happen. We need civil society to advocate for what rightsbased family planning means and how to implement it. We need this to hold governments accountable.

Another recommendation is to work with human rights mechanisms, to "take this to the Human Rights Council to give it more visibility and to link it with larger human rights processes," as noted by a development partner respondent. UNFPA has been engaged with National Human Rights Institutions (NHRI) to strengthen their capacity to include SRHR, including family planning, in their monitoring effects. ${ }^{64}$ Countries report into the Universal Periodic Review (UPR), a mechanism put in place by the United Nations since 2006 to assesses the fulfillment of human rights obligations and commitments by each United Nations Member State every four and a half years. In reviews of the first two cycles of the UPR to assess attention to SRHR issues, UNFPA identified that contraception gets scant attention compared to some other components of SRHR. ${ }^{65,66}$ Still, the UPR process offers a platform to bring together state and non-state actors together and provides civil society an opportunity to advocate for issues raised during the process. 
FP2030 has renewed focus on accountability, emphasizing the need for robust mutual accountability mechanisms that include both governments and civil society and promote rights. FP2030's commitments page describes making a commitment to the FP2030 partnership as an opportunity to help make accountability mechanisms stronger, more systematic, and more transparent. Accountability is also a way of ensuring that laws, policies, programs, and services fulfill the needs and rights of intended beneficiaries and do no harm" (https://commit ments.fp2030.org/accountability-approach). A brief on social accountability is being developed by the Family Planning High Impact Practice Initiative (HIPs), ready in early 2022, to guide programs interested in implementing social accountability initiatives.

\section{Focus on Equity and Highlight Adolescent and Youth Leadership}

Some respondents stressed the need to focus on meeting the needs of marginalized groups and those overlooked in programming, such as adolescents, first-time parents, and men, in addition to people in humanitarian settings. An NGO respondent explained that

There is a tendency to dismiss the poorer, more marginalized women. This is what is missing from rights-based family planning. We need to be more refined in looking at the kinds of marginalization they experience and then figure out how we meet their specific needs and challenges.

FP2030 includes equity in three of its guiding principles (http://www.familyplanning2020.org/Building2030). The first principle is: Voluntary, person-centered, rights-based approaches, with equity at the core. Another principle is "Empowering women and girls along with engaging men, boys, and communities" as part of an equity approach. A third principle highlights

Building intentional and equitable partnerships with adolescents, youth, and marginalized populations to meet their needs, including for accurate and disaggregated data collection and use.

Tools, including a measurement framework to help identify groups facing inequities and that were linked with the rights principles of AAAQ as well as various social characteristics of sub-groups, were developed by the Health Policy Plus (HP+) project (http://www.healthpolicyplus. com/fpEquity.cfm). Using data from the Demographic and Health Survey (DHS) in Uganda, they identified inequities in access, acceptability, and quality health care and in demand satisfied, based on age, education, marital status, wealth, residence, religion, and ethnic status.

Respondents noted that rights-based family planning should continue to focus on youth as key drivers of change and of the future. Respondents gave FP2020 credit for its work to engage youth, including having youth members of FP2020's Reference Group and as part of country focal point structures. An NGO respondent noted that

Youth can advance rights - they are the audience where all these 'taboo' topics come up. This is where all the rights issues are really launched .... Advocacy and conversations have to happen at the national level and creating contacts and developing relationships can create change.

Another NGO respondent reinforced that without youth as the center of discussion of rights and FP2030, "nothing will be achieved."

FP2030 is strengthening the focus on adolescents, including that more stringent commitments will be requested of countries. The commitments page reinforces that meeting FP2030 goals will require partners to intensify efforts promote adolescent and youth (AY) sexual and reproductive health (SRH) services, which includes contraception.

Strong commitments ... send a clear message about the vital importance of improving adolescent and youth SRH knowledge, fostering their agency and ability to make informed decisions, facilitating their access to highquality SRH services ... and ensuring a supportive policy and social environment.

\section{Support Development and Dissemination of Practical Tools and Training Materials}

While there are many available global tools on rights-based family planning, some respondents thought countries could benefit from an array of simpler tools to guide implementation, advocacy, and training. A national government respondent also noted that disseminating the tools and providing assistance for using them will be important. A development partner respondent said reflected that "it would be good to have a tool, but something short, to help countries with rights-based family planning." Some other respondents cautioned about simple tools, as explained by a development partner respondent, who said that "there is a view that rights should be reduced to a checklist, but that is unrealistic."

FP2030 is updating its CIP toolkit to help guide development of country CIPs. A program assessment tool 
focused on rights-based family planning will be available to countries and is being included in the CIP toolkit. This tool emphasizes that a human rights-based approach to family planning is:

A systematic process to ensure that attention to human rights principles related to FP is embedded in all programmatic phases (i.e. needs assessment, programme design, workplan development, implementation, monitoring and evaluation) at all levels of the programme (i.e. policy, service delivery, community and individual). ${ }^{67}$

Training and supervision materials focused on rights-based family planning will be published in 2021 through a project funded by the Bill and Melinda Gates Foundation. Other tools related to dimensions of rights have been noted throughout this paper, although these are not intended to be an exhaustive list of tools.

\section{Continue Working on Rights Metrics and Studies and Disseminate Results}

Respondents stressed the need to advance work on indicators for rights-based family planning, in addition to metrics and data, with attention to the subnational level.

If the family planning community is going to hold governments accountable, there is a need for a clearly-defined rights-based family planning framework and indicators that can be tracked at the global and national levels,

noted one development partner respondent, adding

Program success is still being judged by mCPR, but that doesn't highlight what the family planning community is trying to address with rights-based family planning programming.

Respondents stressed the importance of research on rightsbased family planning and disseminating the findings to a range of stakeholders. Said one NGO respondent, "there would be stronger appreciation if policymakers learn about evidence that the rights-based approach works." Another NGO respondent added,

The results should be disseminated not just to government officials and technocrats, but also down to communities, family planning services providers, and users in simple language, because these are the stakeholders who really need to understand rights-based family planning to change their ideation and societal perspective.

While the rights-based family planning measurement agenda has advanced significantly over the past decade, additional work is needed on enhanced measures of rightsbased family planning - both indicators for monitoring the fulfillment of rights in family planning programming, and more studies must be undertaken to assess the outcomes of such programming. Countries would benefit from guidance on the range of indicators available to measure rights. Furthermore, as noted by the respondents, wide dissemination of the findings from the studies is also needed. Measurement of rights-based family planning will continue under FP2030, with core and other indicators for FP2030 being developed in 2021.

\section{Understand That Institutionalizing Rights Will Take Time}

Respondents stressed that institutionalizing rights in programming will take time. One development partner respondent compared it to the time gender mainstreaming has taken, noting "that same time and energy will be needed to integrate rights-based family planning." Another speculated that realistically, an investment is needed for the long term, 10 to 20 years rather than thinking of rights as a silver bullet or a quick fix. Coordination among donors and programmers is essential as a comprehensive, rights based approach effectively requires considerable resources and expertise from providers.

\section{COVID Has Reinforced the Importance of Family Planning and Rights}

The global COVID-19 pandemic had not begun when the respondent interviews were conducted in 2019 thus its effect is not reflected in the recommendations. Experience since the pandemic started has reinforced the importance of ensuring reproductive rights and access to contraception as an essential part of SRH services. When services are deemed non-essential, "health systems may be unable to fulfill these rights, and communities will lose a formal justification for claiming them." 68 The language and legal teeth - of human rights provide the foundation for taking action to ensure access to including family planning as part of SRH:

Through fostering community participation; focusing on non-discrimination; working to ensure the availability, accessibility, acceptability, and quality of services; providing access to information; and striving to ensure transparency and accountability in the response to the pandemic. ${ }^{69}$

Contraceptive education and availability also is a crucial component. An estimated 15 million unintended pregnancies over a year could result from a $10 \%$ reduction in the 
proportional use of short- and long-acting contraception in lower and middle income countries. ${ }^{70}$ Plans for ensuring access to contraception has implications for providing clients with full, free, and informed choice of methods and should include a renewed focus on contraceptive methods conducive to self-care. ${ }^{71}$

\section{Discussion}

As this paper shows, the 2012 London Summit on Family Planning was, launched somewhat controversially with a numeric goal, but with pressure from activists and other members of the global family planning community, FP2020 became instrumental in sparking work to ensure that achieving the goal was undertaken in through programming that respects, protects, and fulfills human rights.

Work since 2012 has provided the guidance, tools, and language to strengthen family planning programs through a human rights lens and to hold governments accountable for programs that support individuals and couples to exercise their rights to choose the timing and spacing of their pregnancies, to have the information, services, and agency to act on that right, and to be treated respectfully, equally, and without discrimination by providers. As the family planning field looks beyond to 2030, this paper provides a roadmap for not only building on the gains made over the past decade, but also to effectively tackle the challenges remaining to ensure that programming to achieve the vision of the FP2030 Partnership is indeed rightsbased.

The recommendations in this paper come from respondents deeply steeped in family planning policies, programming, advocacy, monitoring and evaluation, and research. They clearly and consistently underscored the need to keep rights at the center of family planning - and to keep working to garner stable global support, including among donors, programmers, clinic providers, and the public, for rights-based programming. The experience from the past decade shows both how fragile political support for family planning and SRH can be and the harm wide shifts in political winds can have on programming and on individuals' wellbeing. Furthermore, while the last decade has seen a flurry of work at the global level to define rights-based family planning and to develop tools and evidence, there is a clear need to focus on rights and implementation at the country level, including promoting political and financial support and ensuring through funding, policies, guidance, training, and supervision that client autonomy and choice among a range of methods are central, avoiding overpromotion of any particular methods. At both the global and country level, rights have too often been seen as an add-on to family planning programming rather than as an umbrella under which all programming should fall. Amplifying adolescent and youth voices will be important since they are most often affected by curtailment of their rights related to family planning. Strengthening civil society, including adolescent and youth voices, will be key to engaging governments to both support and fund rights-based programming. Ensuring rights literacy will give stakeholders flexibility to address rights directly if possible given the context, and indirectly if necessary by highlighting the dimensions of rights, as needed.

Respondents articulated the need to strengthen accountability mechanisms throughout all levels of the public health system:, governments must uphold their policy and program commitments and communities should be supported to engage in social accountability that links communities with local government and providers at the local level. Work should continue to develop metrics and generate evidence and to make sure that stakeholders, notably policymakers and other leaders, are have the evidence of the efficacy of rightsbased programming and can ensure the tools needed to measure programs are widely available. More documentation of rights-based programming will provide lessons learned and exemplify successful programming.

Institutionalizing rights-based family planning will take enhanced commitment from both donors and countries for programming over the long term. Experience around the world has highlighted the particular effects of the global COVID-19 pandemic on women and has reinforced the importance of ensuring reproductive rights and access to SRH services, including contraception, as essential services. The language - and legal teeth - of human rights provide the foundation for ensuring access to family planning. The momentum from 2012-2020 provides a foundation for further strengthening and advancing rights-based family planning programming through 2030 to support individuals and couples to exercise their rights to choose the timing and spacing of their pregnancies, to have the information, services and agency to act on that right, and to be treated respectfully, equally, and without discrimination by providers.

\section{Limitations}

This analysis has some limitations. While an attempt was made to include a range of respondent types, key 
informant interviews primarily represented civil society, implementing partners, and bilateral/multilateral organizations, with few government representatives. Given that governments are duty-bearers for ensuring rights are and in most countries, the majority of services are delivered by the public sector, having more representation from governments would have been useful to inform rights-based programming. Additionally, this analysis was conducted from the perspective of the FP2020 Partnership. An assessment of the perspectives of country implementers who may or may not be aware of global partnerships would provide a more robust picture of rights-based family planning at the country level.

\section{Acknowledgments}

Funding for the data used in this paper was provided by the Bill and Melinda Gates Foundation to the United Nations Foundation, Family Planning 2020 Secretariat.

\section{Disclosure}

The authors report no conflicts of interest in this work.

\section{References}

1. Krishnan S. Highs and lows at the London Family Planning Summit. Blog post on ASAP; 2012. Available from: http://asapasia.org/blog/highs-and-lows-at-the-london-family-planning-summit 1. Accessed April 11, 2021.

2. Khosla R. Looking for human rights at the Family Planning Summit. Blog post. Livewire; 2012. Available from: http://livewire.amnesty. org/2012/07/11/looking-for-human-rights-at-familyplanning-summit/. Accessed December 9, 2012.

3. Girard F. Will the London Family Planning Initiative measure up? RH Reality Check; 2012. Available from: . http://www.rhrealitycheck.org/ article/2012/07/20/will-london-family-planning-initiative-measure-up. Accessed April 11, 2021.

4. Women's human rights must be at the centre of the Family Planning Summit: civil Society Declaration. Available from: https://reproductive rights.org/wp-content/uploads/2020/12/Civil-Society-

Declaration_06_19_2012.pdf. Accessed August 31, 2021.

5. Hardee K, Jordan S. Contributions of FP2020 in advancing rights-based family planning: upholding and advancing the promises of Cairo. Washington, DC; 2020. Available from: https://www.familyplan ning2020.org/resources/contributions-fp2020-advancing-rights-basedfamily-planning-upholding-and-advancing. Accessed August 31, 2021.

6. United Nations (UN). Final Act of the International Conference on Human Rights. New York: United Nations; 1968. Available from: https://legal.un.org/avl/pdf/ha/fatchr/Final_Act_of_TehranConf.pdf. Accessed August 31, 2021.

7. Office of the High Commissioner for Human Rights (OHCHR). Frequently Asked Questions on a Human Rights-Based Approach to Development Cooperation. New York and Geneva: OHCHR; 2006.

8. UNFPA and Center for Reproductive Rights (CRR). The Right to Contraceptive Information and Services for Women and Adolescents. New York: CRR; 2011.

9. UNFPA. Choices Not Chance: family Planning Strategy 2012-2020. New York: UNFPA; 2012. Available from: https://www.unfpa.org/pub lications/choices-not-chance. Accessed August 31, 2021.
10. Cottingham J, Germain A, Hunt P. Use of human rights to meet the unmet need for family planning. Lancet. 2012;380(9837):172-180. doi:10.1016/S0140-6736(12)60732-6

11. Hardee K, Kumar J, Newman K, et al. Voluntary, human rights-based family planning: a conceptual framework.". Stud Fam Plann. 2014;45(1):1-18. doi:10.1111/j.1728-4465.2014.00373.x

12. Erdman J, Cook RJ. Reproductive rights. Int Encyclopedia Public Health. 2008. Elsevier.https://www.sciencedirect.com/science/article/ pii/B9780123739605004780

13. World Health Organization (WHO). Ensuring Human Rights in the Provision of Contraceptive Information and Services. Geneva; 2014. Available from: https://www.who.int/reproductivehealth/publications/family_planning/ human-rights-contraception/en/. Accessed August 31, 2021.

14. FP2020. Rights and empowerment principles. Washington, DC; 2015. Available from: https://www.familyplanning2020.org/sites/ default/files/FP2020_Statement_of_Principles_11x17_EN_092215. pdf. Accessed August 31, 2021.

15. UNFPA and WHO. Ensuring Human Rights Within Contraceptive Service Delivery: implementation Guide. Geneva; 2015. Available from: https://www.who.int/reproductivehealth/publications/family_plan ning/hr-contraceptive-service-delivery/en/. Accessed August 31, 2021.

16. World Health Organisation. Quality of care in contraceptive information and services, based on human rights standards: a checklist for health care providers. Geneva: World Health Organisation; 2017. 9789241512091eng.pdf;jsessionid=899DABCC6E6B45574FF8DFAFC5EDBA8F. https://www.who.int/reproductivehealth/publications/family_planning/ human-rights-contraception/en/ Accessed September 2, 2021.

17. FP2020. Rights-based Contraceptive Information and Services An Accountability Tool. Washington, DC; 2015. Available from: http://www. familyplanning2020.org/sites/default/files/FP2020_AccountabilityTool_ SinglePage_12.18.15_0.pdf. Accessed August 31, 2021.

18. Kumar J, Bakamjian L, Hardee K, Jurczynska K, Jordan S. Rights-based Family Planning.” In FP2020. 2018b. Rights-sizing Family Planning. A Toolkit for Designing Programs to Respect, Protect, and Fulfill the Rights of Girls and Women. Washington, DC; 2018. Available from: http://familyplanning2020.org/sites/default/files/Rights-

sizing_Family_Planning_Toolkit_EN.pdf. Accessed August 31, 2021.

19. FP2020 and UNFPA. Rights in practice: what makes a REAL difference to programs?" Meeting Report; 2019. Available from: http:// www.familyplanning2020.org/sites/default/files/Our-Work/RBFP/ RBFPKigali-Report-FINAL.pdf. Accessed August 31, 2021

20. FP2020 and IPPF. Consultation on realizing sustainable programming for rights-based family planning. Meeting Report. London; 2016. Available from: https://www.familyplanning2020.org/sites/default/ files/FP2020_Rights-Based-Family-Planning-Consultation-FINAL. pdf. Accessed August 31, 2021.

21. FP2020 and IPPF. Rights, the unfinished agenda. Meeting Report. London, Washington, DC; 2017. Available from: https://www.famil yplanning2020.org/sites/default/files/London_2017_Consultation_ Report.pdf. Accessed August 31, 2021.

22. Hardee K, Jurczynska K, Sinai I, et al. Improving voluntary, rightsbased family planning: experience from Nigeria and Uganda.". Open Access J Contraception. 2019; Volume 10(10):55-67. doi:10.2147/ OAJC.S215945

23. Gruskin S, Ferguson L, Kumar S, Nicholson A, Ali M, Khosla R. A novel methodology for strengthening human rights based monitoring in public health: family planning indicators as an illustrative example. PLoS One. 2017;12(12):e0186330. doi:10.1371/journal

24. Weinberger M, Ross J. The National Composite Index for Family Planning (NCIFP). Glastonbury, CT: Avenir Health; 2015. Available from: https://avenirhealth.org/download/publications/PDF/NCIFP\% 20Report_Final\%20(2015.09.08).pdf. Accessed August 31, 2021.

25. Rosenberg R. The National Composite Index for Family Planning (NCIFP): 2017 Global Report. Glastonbury, CT: Avenir Health; 2020. Available from: http://www.track20.org/download/pdf/2017 NCIFP_Global_Report_FINAL.pdf. Accessed August 31, 2021. 
26. World Health Organisation. Monitoring human rights in contraceptive services and programmes. Geneva: World Health Organisation; 2017. Available from: https://www.who.int/reproductivehealth/publications/ contraceptive-services-monitoring-hr/en/. Accessed August 31, 2021.

27. Wright K, Boydell V, Muhangi L, et al. Measuring rights-based family planning service delivery: evidence from health facilities in Uganda. Paper presented at the 2017 annual conference of the Population Association of America; 2017 April 27-29; Chicago.

28. Senderowicz L. Contraceptive autonomy: conceptions and measurement of a novel family planning indicator. Stud Fam Plann. 2020;51 (2):161-176. doi:10.1111/sifp.12114

29. Holt K, Dehlendorf C, Langer A. Defining quality in contraceptive counseling to improve measurement of individuals' experiences and enable service delivery improvement. Contraception. 2017;96 (3):133-137. doi:10.1016/j.contraception.2017.06.005

30. Holt K, Zavala I, Quintero X, Hessler D, Langer A. Development and validation of the client-reported quality of contraceptive counseling scale to measure quality and fulfillment of rights in family planning programs. Stud Fam Plann. 2019;50(2):137-158. doi:10.1111/sifp.12092

31. Jarvis L, Wickstrom J, Shannon C. Client Perceptions of Quality and Choice at Static, Mobile Outreach, and Special Family Planning Day Services in 3 African Countries.". Global Health Sci Practice. 2018;6 (3):439-455. doi:10.9745/GHSP-D-18-00047

32. Chakrobotti NM, Chang K, Bellows B, et al. Association between the quality of contraceptive counseling and method continuation: findings from a prospective cohort study in social franchise clinics in Pakistan and Uganda. Global Health Sci Practice. 2019;7(1):87-102. doi:10.9745/ghsp-d-18-00407

33. Jain A, Aruldas K, Tobey E, Mozumdar A, Acharya R. Adding a Question About Method Switching to the Method Information Index Is a Better Predictor of Contraceptive Continuation. Global Health Sci Practice. 2019a;7(2):289-299. doi:10.9745/GHSP-D-19-00028

34. Jain AK, Townsend J, RamaRao S. Proposed metrics to measure quality: an overview. Working Paper No. 3, prepared for the Measuring and Monitoring Quality of Care Project. New York: Population Council; 2018. Available from: https://www.popcouncil. org/uploads/pdfs/2018RH_QoCMetricsWP.pdf. Accessed August 31, 2021.

35. Jain A, Aruldas K, Mozumdar A, Tobey E, Acharya R. Validation of two quality of care measures: results from a longitudinal study of reversible contraceptive users in India. Stud Fam Plann. 2019b;50 (2):179-193. doi:10.1111/sifp.12093

36. Elewonibi B, Sato R, Manongi R, Msuya S, Shah I, Canning D. The distance-quality trade-off in women's choice of family planning provider in North Eastern Tanzania. BMJ Global Health. 2020;5: e002149. doi:10.1136/bmjgh-2019-002149

37. Edmeades J, Hinson L, Sebany M, Murithi L. A conceptual framework for reproductive empowerment: empowering individuals and couples to improve their health. Washington, DC: International Center for Research on Women; 2018. Available from: https://www. icrw.org/wp-content/uploads/2018/10/Reproductive-EmpowermentBackground-Paper_100318-FINAL.pdf. Accessed August 31, 2021.

38. MEASURE Evaluation. Reproductive Empowerment Scale. Chapel Hill, NC: MEASURE Evaluation; 2020. Available from: https:// www.measureevaluation.org/resources/publications/tl-20-81\#: :text= The $\% 20$ Reproductive $\% 20$ Empowerment $\% 20$ Scale $\% 20$ consists, women's $\% 20$ reproductive $\% 20$ health $\% 20$ and $\% 20$ fertility. Accessed August 31, 2021.

39. Silverman JG, Challa S, Boyce SC, Averbach S, Raj A. Associations of reproductive coercion and intimate partner violence with overt and covert family planning use among married adolescent girls in Niger. EClinicalMedicine. 2020;22:100359. doi:10.1016/j.eclinm.2020.100359
40. Gullo S, Galavotti C, Sebert Kuhlmann A, Msiska T, Hastings P, Marti CN. Effects of a social accountability approach, CARE's Community Score Card, on reproductive health-related outcomes in Malawi: a cluster-randomized controlled evaluation. PLOSONE. 2017;12(2):e0171316. doi:10.1371/journal.pone.0171316

41. Weggs C, Creanga AA, Galavotti C, Wamalwa E. Community Dialogue to Shift Social Norms and Enable Family Planning: an Evaluation of the Family Planning Results Initiative in Kenya. PLoS One. 2016;11(4):e153907.

42. Boydell V, Neema S, Wright K, Hardee K. Closing the Gap between People and Programs: lessons from Implementation of Social Accountability for Family Planning and Reproductive Health in Uganda. Afr J Reprod Health. 2018;22(1):73-84.

43. Steyn PS, Boydell V, Cordero JP, et al. Rationale and design of a complex intervention measuring the impact and processes of social accountability applied to contraceptive programming: caPSAI Project. Gates Open Res. 2020;4:26. doi:10.12688/gatesopenres.13075.1

44. Bruce J. Fundamental elements of the quality of care: a simple framework.". Stud Fam Plann. 1990;21(2):61-91. doi:10.2307/196 6669

45. Lynam P, McNeil Rabinovitz L, Shobowale M. Using self-assessment to improve the quality of family planning clinic services. Stud Fam Plann. 1993;24(4):252-260. doi:10.2307/2939193

46. Bertrand JT, Hardee K, Magnani RJ, Angle MA. Access, quality of care and medical barriers in family planning programs. Int Fam Plan Perspect. 1995;21(2):64-69, 74. doi:10.2307/2133525

47. RamaRao S, Mohanam R. The quality of family planning programs: concepts, measurements, interventions, and effects. Stud Fam Plann. 2003;34(4):227-248. doi:10.1111/j.1728-4465.2003.00227.x

48. Jain AK, RamoRao S, Kim J, Costello M. Evaluation of an intervention to improve quality of care in family planning programme in the Philippines. J Biosoc Sci. 2012;44:27-41. doi:10.1017/S00219320 11000460

49. Kumar J. How Does Quality of Care Relate to a Rights-based Approach to Family Planning Programs? Report prepared under a grant from the David \& Lucile Packard Foundation to the Population Council, May 15. New York: The Population Council; 2015. Available from: https://www.popcouncil.org/uploads/pdfs/ 2015RH_QOC-RightsBasedFP_wp1.pdf. Accessed August 31, 2021.

50. Jain AK, Hardee K. Revising the FP quality of care framework in the context of rights-based family planning. Stud Fam Plann. 2018;49 (2):171-179. doi:10.1111/sifp.12052

51. FP2030, UNFPA, and What Works Association. The Comprehensive Human Rights-based, Voluntary Family Planning Program Framework. A Brief. Washington, DC: FP2030; 2021. Available from: https://commitments.fp2030.org/sites/default/files/06.25.21_ Framework_Brief.pdf. Accessed August 31, 2021.

52. Ministry of Health, Kenya. National Family Planning Costed Implementation Plan 2017-2020. Nairobi: Ministry of Health; 2017.

53. Republique du Mali. Plan d'Action National de Planification Familiale du Mali 2014-2018 Bamako: republique du Mali, Ministere de la Sante et de l'Hygiene; 2014.

54. Direction Générale de la Santé et de l'Hygiène Publique [Mali]. Plan d'Action National Budgétisé de Planification Familiale 2019-2023 du Mali. Bamako: ministère de la Santé et des Affaires Sociales, Division de la Planification Familiale et la Sous-Direction de la Santé de la Reproduction; 2019.

55. FP2020. Rights-sizing Family Planning. A Toolkit for Designing Programs to Respect, Protect, and Fulfill the Rights of Girls and Women. Washington, DC: FP2020; 2018. Available from: http://family planning2020.org/sites/default/files/Rights-sizing_Family_Planning_ Toolkit_EN.pdf. Accessed August 31, 2021. 
56. Eichler R, Seligman B, Beith A, Wright J. Performance-based incentives in family planning: lessons for developing countries. Bethesda, Md health Systems 20/20 project, Abt Associates; 2010. Available from: https://www.hfgproject.org/performance-based-incentives-ensuringvoluntarism-family-planning-initiatives/. Accessed August 31, 2021.

57. Chowdhury S, Vergeer P, Schmidt H, Barroy H, Bishai D, Halpern S. Economics and ethics of results-based financing for family planning: evidence and policy implications. Health, nutrition, and population (HNP) discussion paper. Washington, DC: World Bank; 2013. Available from: https://openknowledge.worldbank.org/handle/10986/ 17564. Accessed August 31, 2021.

58. Cole MS, Boydell V, Hardee K, Bellows B. The extent to which performance-based financing programs' operations manuals reflect rights-based principles: implications for family planning services. Global Health Sci Practice. 2019;7(2):329-339.

59. Eichler R, Wright J, Bellows B, Cole M, Boydell V, Hardee K. Strategic purchasing to support voluntarism, informed choice, quality and accountability in family planning: lessons from results-based financing. Rockville, MD: Health Finance \& Governance Project, Abt Associates Inc; 2018. Available from: https:/www.hfgproject.org/strategicpurchasing-to-support-family-planning/. Accessed August 31, 2021.

60. Appleford G, RamaRao S, Bellows B. The inclusion of sexual and reproductive health services within universal health care through intentional design. Sexual Reproductive Health Matters. 2020;28:2. doi:10.1080/26410397.2020.1799589

61. Holtz J, Sarker I. Integrating family planning into universal health coverage efforts. Bethesda, MD: Sustaining Health Outcomes through the Private Sector Plus Project, Abt Associates; 2018. Available from: https://www.shopsplusproject.org/resource-center /integrating-family-planning-universal-health-coverage-efforts. Accessed August 31, 2021.

62. Health Policy Plus. The Motion Tracker: driving accountability, action, and achievement. Washington, DC: Palladium, Health Policy Plus; 2019. Available from: http://www.healthpolicyplus.com/ns/pubs/1333013605_MotionTrackerBrief.pdf. Accessed August 31, 2021.

63. Ralidera OR. Removing Taxes for Contraceptives in Madagascar: strategic Advocacy Leads to Increased Budget for Family Planning. IBP Network Implementation Story; 2021. Available from: https:// d1c2gz5q23tkk0.cloudfront.net/assets/uploads/3082408/asset/ Options_Madagascar.pdf?1618608091. Accessed August 31, 2021.
64. UNFPA. A Guide in Support of National Human Rights Institutions Country Assessments and National Inquiries on Human Rights in the Context of Sexual and Reproductive Health and Well-being. New York: UNFPA; 2019. Available from: https:// www.unfpa.org/publications/guide-support-national-human-rightsinstitutions. Accessed August 31, 2021.

65. UNFPA. Lessons from the First Cycle of the Universal Periodic Review: from Commitment to Action on Sexual and Reproductive Health and Rights. New York: UNFPA; 2014. Available from: https:// www.unfpa.org/sites/default/files/pub-pdf/UNFPA_PUB_2019_EN_ Lessons_from_the_second_cycle_of_the_universal_periodic_review. pdf. Accessed August 31, 2021.

66. UNFPA. From Commitment to Action on Sexual and Reproductive Health and Rights Lessons From the Second Cycle of the Universal Periodic Review. New York: UNFPA; 2019. Available from: https:// www.unfpa.org/sites/default/files/pub-pdf/UNFPA_PUB_2019_EN_ Lessons_from_the_second_cycle_of_the_universal_periodic_review. pdf. Accessed August 31, 2021.

67. UNFPA and What Works Association. Program Assessment Tool for a Human Rights-based Approach to Voluntary Family Planning. New York: UNFPA; 2021.

68. Schaaf M, Boydell V, Van Belle S, Brinkerhoff DW, George A. Accountability for SRHR in the context of the COVID-19 pandemic. Sexual Reproductive Health Matters. 2020;28(1):1-4. doi:10.1080/26410397.2020.1779634

69. Hussein J. COVID-19: what Implications for sexual and reproductive health and rights globally? Sexual Reproductive Health Matters. 2020;28(1):1-3. doi:10.1080/26410397.2020.1746065

70. Riley T, Sully E, Ahmed Z, Biddlecom A. Estimates of the potential impact of the COVID-19 pandemic on sexual and reproductive health in low- and middle-income countries. Int Perspect Sex Reprod Health. 2020;46:73-76. doi:10.1363/46e9020

71. Weinberger M, Hayes B, White J, Skibiak J. Doing things differently: what it would take to ensure continued access to contraception during COVID-19. Global Health: Science Practice. 2020;8(2):2. doi:10. 9745/GHSP-D-20-00171
Open Access Journal of Contraception

\section{Publish your work in this journal}

Open Access Journal of Contraception is an international, peerreviewed, open access, online journal, publishing original research, reports, reviews and commentaries on all areas of contraception. In addition to clinical research, demographics and health-related aspects, the journal welcomes new findings in animal and preclinical
Dovepress

studies relating to understanding the biological mechanisms and practical development of new contraceptive agents. The manuscript management system is completely online and includes a very quick and fair peer-review system. Visit http://www.dovepress.com/testimonials. php to read real quotes from published authors. 